ANUARIO DE ESTUdios MEDIEVALES

48/1, enero-junio de 2018, pp. 301-329

ISSN 0066-5061

https://doi.org/10.3989/aem.2018.48.1.10

\title{
LA PUISSANCE DES INSTITUTIONS ECCLÉSIASTIQUES DANS LES CRITÈRES DE HIÉRARCHISATION DES VILLES: LE CAS DU HAUT CLERGE SECULIER EN CATALOGNE (XV ${ }^{\mathrm{e}}$ SIÈCLE)
}

\author{
THE POWER OF CHURCH INSTITUTIONS IN CITY HIERARCHISATION: \\ HIGH-RANKING SECULAR CLERGY IN CATALONIA (1 $15^{\text {th }}$ CENTURY)
}

\author{
JULia CONESA SORIANO \\ Centre Roland Mousnier (UMR 8596) \\ https://orcid.org/0000-0001-7836-3707
}

\begin{abstract}
Résumé: Les cathédrales sont étroitement associées aux cités où elles sont localisées. Sommets de la hiérarchie ecclésiastique du diocèse, évêques et chanoines sont aussi, en Catalogne, susceptibles de participer à la vie politique du Principat, en siégeant aux assemblées de la Diputació del General et aux Corts. De ce fait, les chapitres cathédraux disposent d'une forme de rayonnement politique à travers la carrière de leurs membres. Ils entretiennent entre eux des relations de coopération qui dessinent un véritable réseau de sièges épiscopaux catalans. La puissance des institutions religieuses séculières s'érige alors en critère de hiérarchisation des villes: un critère souvent négligé par l'historiographie, qui s'ajoute aux critères économiques, politiques ou démographiques.
\end{abstract}

Mots-clés: cathédrales; Catalogne; villes; hiérarchie; haut clergé séculier; $\mathrm{XV}^{\mathrm{e}}$ siècle.

Abstract: Medieval cathedrals were closely linked to the city where they were situated. In Catalonia, bishops and canons were not only the highest level of the ecclesiastical hierarchy in the diocese, but they were also able to take part in the Catalan political assemblies: the Diputació del General and the Corts. As a result, the cathedral chapters had a political influence through the careers of their members. They were interconnected and cooperated with one another, creating a real network of Catalan cathedrals. Therefore, this influence can be considered as a criterion to rank cities, a criterion often overlooked by historical studies, which can take its place alongside economic, political and demographic criteria.

Keywords: cathedrals; Catalonia; cities; hierarchy; cathedral clergy; $15^{\text {th }}$ century.

\section{SOMMAIRE}

1. Introduction.- 2. Évêchés, hiérarchies et place des villes: vers un classement des cathédrales catalanes?.- 2.1. Les évêchés catalans: un reflet de la macrocéphalie barcelonaise?.- 2.2. Le poids des évêchés dans les "bras ecclésiastiques" des institutions politiques: une hiérarchie de l'influence?.- 3. Sièges épiscopaux, réseaux d'hommes, réseaux de villes.- 3.1. Les Corts, liens de solidarité et interdépendance des évêchés.3.2. Les carrières religieuses: entre réseaux personnels et réseau d'évêchés catalans.- 3.3. Évêques et réseau d'évêchés catalans.- 4. Le haut clergé séculier et le rayonnement politique des centres urbains.- 4.1. Ville et haut clergé séculier: des échanges de bons procédés.- 4.2. Mobiliser les réseaux du haut clergé urbain: un moyen d'accéder à d'autres villes.- 5. Conclusion.- 6. Bibliographie citée.

Cómo citar este artículo: Conesa Soriano, Julia (2018), La puissance des institutions ecclésiastiques dans les critères de hiérarchisation des villes: le cas du haut clergé séculier en Catalogne (XV siècle), "Anuario de Estudios Medievales" 48/1, pp. 301-329. https://doi.org/10.3989/aem.2018.48.1.06

Copyright: (C) 2018 CSIC. This is an open-access article distributed under the terms of the Creative Commons Attribution 4.0 International (CC BY 4.0) License. 


\section{INTRODUCTION ${ }^{1}$}

Dans les années 1990, André Vauchez forgeait la notion de "religion civique" pour désigner l'intégration de la religion à la vie de la cité, dans une optique de légitimation des pouvoirs politiques urbains ${ }^{2}$. Aujourd'hui nuancée, cette notion n'en mettait pas moins en évidence la place prégnante que peut jouer le haut clergé séculier dans la cité, au-delà de ses seules fonctions d'encadrement des fidèles. Responsable du salut des âmes des fidèles, dispensateur de charité dans la ville ${ }^{3}$, supérieur hiérarchique des églises du diocèse, le haut clergé séculier urbain -en d'autres termes, les évêques et les chanoines de leur chapitre cathédral- est amené à jouer un rôle majeur dans la vie des cités médiévales ${ }^{4}$. Symboliquement, chanoines et évêques constituent, selon les mots de Vincent Tabbagh, les deux incarnations de l'Église de la civitas ${ }^{5}$. Dans le droit canon, l'évêque est en effet associé à sa cathédrale par un lien que les sources canoniques assimilent à celui des noces ${ }^{6}$. Il dispose d'un pouvoir de juridiction et de nomination du clergé sur l'ensemble du diocèse, dont le symbole est la cathédrale. Les chanoines lui sont associés. Ils administrent la cathédrale qui, dans la pratique, constitue un véritable centre administratif et fonctionnel, à la fois du diocèse et de la seigneurie qui lui est rattachée ${ }^{7}$. La ville où la cathédrale est installée représente alors par définition le centre névralgique du maillage de l'espace où s'exerce la juridiction de l'église cathédrale: le diocèse et ses paroisses. Le Principat de Catalogne compte sept

\footnotetext{
${ }^{1}$ Abréviations utilisées: $\mathrm{AHCB}=$ Archives Historiques de la Ville de Barcelone; $\mathrm{AHPNB}=$ Archives des Protocoles Notariés de Barcelone; $\mathrm{ADB}=$ Archives diocésaines de Barcelone; ASV = Archives Secrètes du Vatican.

${ }^{2}$ Vauchez 1995, p. 4. Le concept a connu des développements féconds (voir notamment Caby 2008) mais est aujourd'hui questionné par une part de l'historiographie, à la suite de Monnet 2010 ou encore de Dumolyn 2010. Voir une synthèse des dernières évolutions de l'historiographie sur cette notion dans Balossino 2014, pp. 124-125.

${ }^{3}$ En Catalogne, les cathédrales médiévales administrent les Pies Almoines, institutions charitables chargées de fournir des repas aux pauvres de la ville. Pour une définition générale, voir Baucells 1998-2001, p. 85.

${ }^{4}$ Nous employons ici l'expression "haut clergé séculier" pour éviter d'avoir recours à celle de "clergé cathédral". Cette dernière englobe en effet, au-delà des évêques et chanoines, le clergé auxiliaire et les clercs détenteurs de bénéfices. Or, bien que rattachés eux aussi à la cathédrale, ceux-ci, issus de carrières hétéroclites, ne disposent aucunement des mêmes pouvoirs que les membres du chapitres et l'évêque, notamment en matière politique, si bien qu'on ne peut leur appliquer la même grille d'analyse.

${ }^{5}$ Tabbagh 2015, p. 207.

${ }^{6}$ Ibidem, p. 7.

${ }^{7}$ Pour une réflexion sur le rapport de l'évêque à son territoire, voir comment, dès le milieu du XIe siècle, le diocèse tend à constituer le territoire propre de l'évêque, Mazel 2008.
} 
diocèses à la fin du Moyen Âge ${ }^{8}$. Au-dessus, se situe la juridiction du supérieur hiérarchique direct, à savoir l'archevêque, qui a autorité sur sa province ecclésiastique (c'est-à-dire, en Catalogne, la Tarraconaise ${ }^{9}$ ). Ce pouvoir est, lui-aussi, centralisé par la cathédrale siège de l'archevêché. Cette juridiction territoriale des cathédrales se superpose alors au quadrillage de l'espace catalan par les juridictions laïques ${ }^{10}$, et notamment par celle des puissantes villes catalanes.

Le siège épiscopal s'avère donc, par nature, étroitement lié à sa citée ${ }^{11}$. Or, dans tout espace urbanisé, les villes entretiennent entre elles des relations de rivalité, de coopération, de concurrence, dans les domaines économiques et politiques. Certaines d'entre elles polarisent l'espace en attirant les fonctions de commandement et les activités économiques ${ }^{12}$. On peut alors les classer en fonction de leur richesse, de leur influence politique, de leur démographie. Rien n'empêche, a priori, d'y ajouter le critère de la puissance de l'Église urbaine pour observer la hiérarchisation qui s'établit entre les cités médiévales. Mais la démarche devient réellement significative lorsque l'on observe l'influence que peut avoir la puissance de l'Église urbaine sur le rayonnement de la cité d'un point de vue politique. La notion de hiérarchisation urbaine implique en effet non seulement d'établir des critères de classement des villes, mais aussi d'observer les relations de dépendance qui s'établissent entre elles. Dans ce cadre, la question se pose de savoir si le rayonnement de l'Église d'une cité est corrélé au rayonnement de celle-ci sur ses voisines et, surtout, s'il en est un facteur.

Le cas catalan permet d'apporter des éléments de réponse, en raison de la connexion qui existe entre le haut clergé et les assemblées politiques régionales où il siège. À la fin du Moyen Âge, le Principat de Catalogne, territoire de la Couronne d'Aragon, est en effet pourvu deux types d'assemblées politiques régionales, qui disposent chacune d'un "bras ecclésiastique": les

\footnotetext{
${ }^{8}$ Tarragone, Barcelone, Elne, Gérone, Lérida, Tortose et Urgell, Hurtado, Mestre, Miserachs 1995, p. 112. Le diocèse d'Elne est rattaché à la province ecclésiastique de Narbonne, Monjas 2008 , note 10, p. 48.

${ }^{9}$ Sur la formation, l'évolution et le gouvernement de la province ecclésiastique de Tarragone au Moyen Âge, voir: Sabanés 2009.

${ }^{10}$ Dans un article déjà ancien, Jacques Verger met en évidence comment le quadrillage de l'espace par l'Église à travers les paroisses et les diocèses se juxtapose à celui des baillages, sénéchaussées et autres juridictions du pouvoir laïc, comme deux maillages de l'espace simultanés, Verger 1986, pp. 33-34.

${ }^{11}$ Voir le rôle prégnant joué par le clergé dans la vie et la construction de la cité dans l'espace italien: Pellegrini 2004.

${ }^{12}$ Voir les réflexions de Peter Stabel à ce sujet, à partir de l'espace flamand tardo-médiéval, Stabel 2000.
} 
Corts catalanes ${ }^{13}$, assemblées consultatives réunies par le souverain de la Couronne d'Aragon, et la Diputació del General ${ }^{14}$. On le voit: l'Église ne sera pas considérée dans ces lignes pour son rôle spirituel ni pour sa richesse temporelle, mais pour la place qu'elle occupe au sein des institutions qui structurent la société médiévale. Or, l'Église de la Couronne d'Aragon et, en particulier, celle de Catalogne, demeure délaissée par la recherche historique. À la différence des espaces voisins, les études manquent, malgré -ou peut-être à cause de- 1 'abondance des sources ${ }^{15}$. Alors que l'espace français est bien balisé par les travaux du groupe de recherche des Fasti Ecclesiae Gallicanae ${ }^{16}$ et qu'en Castille, une très longue tradition historiographique de monographies sur les chapitres quadrille assez bien l'espace ${ }^{17}$, la Couronne d'Aragon reste le parent pauvre de l'histoire canonicale. L'historiographie qui se centre sur les villes catalanes laisse elle-même peu de place au rôle de l'Église ${ }^{18}$. Il est donc impossible, en l'état actuel de la recherche, de dresser une comparaison exhaustive, appuyée sur des critères communs (effectifs, richesse temporelle, etc.), entre les sièges épiscopaux catalans à une époque donnée et il faut se contenter de données partielles.

Ceci posé, les sièges d'évêchés catalans ne sont pas tous équivalents, que ce soit en termes de démographie, de richesse ou au niveau de leur participation aux assemblées politiques catalanes des Corts et de la Diputació del General. La cathédrale de Barcelone se pose rapidement comme celle qui dispose du plus grand poids (I). Mais au-delà de l'établissement d'un simple classement, les carrières et liens personnels qui unissent les chanoines et évêques

${ }^{13}$ Sur cette institution, voir les différentes contributions réunies dans: Les Corts 1991.

${ }^{14} \mathrm{Au}$ départ commission temporaire accompagnant les Corts pour décider des modalités de levée des subsides décidés par l'assemblée, la Diputació, au XV siècle, est devenue permanente et acquiert un véritable poids politique. Pour son organisation et ses fonctions, voir: Sánchez 2004; Ferrer 2011.

${ }^{15}$ La richesse des fonds d'archives catalans est aujourd'hui quasi proverbiale. Les archives ecclésiastiques n'échappent pas à cette règle mais sont encore sous-exploitées par les chercheurs, sans doute, justement, en raison de leur profusion, Péquignot 2016; Torra 1995; Conde 1995.

${ }^{16}$ Voir l'ouvrage fondateur de cette ligne de recherche: Millet 1982 et, sur les Fasti Ecclesiae Gallicanae, Millet 1996. Voir aussi les seize volumes issus des travaux du groupe de recherche des Fasti Ecclesiae Gallicanae (http://fasti.univ-paris1.fr/) et leur équivalent au Portugal, les Fasti Ecclesiae Portugaliae: Prosopography of the Portuguese Cathedral Clergy (1071-1325) entre 2002 et 2006, Jorge 2001-2002.

${ }^{17}$ Voir le bilan de cette historiographie dans Lop 2003.

${ }^{18}$ Le travail, déjà ancien, de Nikolas Jaspert sur les connexions entre le conseil de la ville de Barcelone et les religieux de la cité fait encore figure d'exception, Jaspert 2001. Des études observant le rôle de l'Église comme institution mais aussi celui des membres du clergé et leurs connexions avec le pouvoir politique, comme celles qui se sont développées pour le Portugal dans les années 2000-2010, par exemple: Farelo 2012, font encore largement défaut pour l'espace catalan. 
catalans dessinent en réalité l'image d'un véritable réseau hiérarchisé: un réseau de connaissance, d'intérêts, de coopération, qui unit non seulement les membres du haut clergé catalan mais aussi, par extension, les chapitres et les villes dont ils sont originaires (II). L'exemple barcelonais montre à quel point ce rayonnement du haut clergé séculier s'articule à celui du centre urbain où se situe la cathédrale observée, participant ainsi pleinement des critères de hiérarchisation des cités médiévales (III).

\section{2. ÉVÊCHÉS, HIÉRARCHIES ET PLACE DES VILLES: VERS UN CLASSEMENT DES CATHÉDRALES CATALANES?}

\subsection{Les évêchés catalans: un reflet de la macrocéphalie barcelonaise?}

Peut-on classer les cathédrales entre elles ? De prime abord, la question elle-même pourrait sembler saugrenue. Considérés du point de vue de la hiérarchie ecclésiastique, en effet, tous les évêchés d'une province ecclésiastiques sont égaux entre eux. Tous sont placés sous l'autorité de l'archevêché. De ce fait, aucune raison de les comparer ne se profile a priori. De surcroît, le pouvoir de la cathédrale, considérée comme siège du pouvoir épiscopal, est par essence circonscrit au territoire de son diocèse: l'évêque y est le supérieur hiérarchique du clergé séculier et, en tant que guide spirituel des fidèles, en bon pasteur du troupeau, il jouit sur son territoire d'une autorité à la mesure de sa charge, selon les termes choisis par Jean Gaudemet pour définir le statut et les fonctions de l'évêque dans l'Occident médiéval ${ }^{19}$. À ces institutions sont attachés de riches temporels; à ce titre, l'évêché doit être considéré non seulement comme un maillon de la hiérarchie ecclésiastique locale mais comme une seigneurie. Or, les territoires des temporels épiscopal et capitulaire, qui recoupent parfois en partie les frontières du diocèse sans que cela soit systématique $^{20}$,restent eux aussi polarisés autour d'un centre de commandement: la ville où siègent l'évêque et son administration. Par définition, les cathédrales ne sont donc guère amenées à entretenir la moindre relation entre elles. La juridiction de l'une s'arrête là où celle de sa voisine commence, c'est-à-dire aux frontières de leurs diocèses respectifs. Reflétant cette réalité institutionnelle, les études qui portent sur les cathédrales embrassent pour leur grande majorité des territoires restreints: la ville où se situe l'établissement, le diocèse, ou

${ }^{19}$ Gaudemet 1979,p. 9.

${ }^{20}$ Sur les liens entre l'évêque et son territoire, voir les réflexions de: Mazel 2008. 
encore l'espace du temporel épiscopal et capitulaire ${ }^{21}$. Pourtant, les effectifs, la richesse et l'influence dans le siècle des différentes cathédrales varient significativement de l'une à l'autre.

Dans le cas catalan, Tarragone, siège métropolitain ${ }^{22}$, est ainsi l'unique supérieur local des autres sièges épiscopaux de la province ecclésiastique (l'échelon supérieur de la hiérarchie religieuse étant directement le Saint-Siège). Néanmoins, la position hiérarchiquement dominante de Tarragone ne se retrouve ni dans le poids démographique des différentes cathédrales, ni dans leur influence sur le siècle. Selon ces critères, au contraire, c'est Barcelone occupe la première place. En termes d'effectifs, avec ses quarante prébendes et ses huit dignités, son chapitre se pose comme le plus grand de Catalogne. À Tarragone, une bulle de Benoît XIII, datée du 29 juin 1410, réforme le chapitre qui compte alors, jusqu'en 1530, vingt-trois chanoines, soit presque deux fois moins que son voisin barcelonais ${ }^{23}$. Il n'est même pas le deuxième en nombre puisque celui de Lérida compterait vingt-cinq chanoines depuis le $\mathrm{XIII}^{\mathrm{e}}$ siècle $^{24}$ et celui de Gérone dénombre vingt-quatre chanoines dont sept dignitaires ${ }^{25}$. À Vic, les dignités se cantonnent au chiffre de trois et les prébendes atteignent l'effectif de vingt-deux membres ${ }^{26}$. Le chapitre d'Urgell, enfin, abrite vint à vingt et un membres au début du $\mathrm{XVI}^{\mathrm{e}}$ siècle $^{27}$.

Or, la taille du chapitre cathédral ne s'explique pas par le nombre d'habitants de la ville (figures 1 et 2): malgré un poids démographique de la cité variant du simple au quadruple (de 2.000 à 11.000 habitants), les chapitres catalans ont tous à peu près le même nombre de membres (autour de vingt). Barcelone constitue une exception, avec le double de chanoines pour un poids démographique beaucoup plus lourd que les autres villes (environ 35.000 habitants). En revanche, Tarragone, archevêché, ne se démarque pas de ses homologues.

\footnotetext{
${ }^{21}$ Voir la longue tradition de monographies centrées sur une seule cathédrale, dont María José Lop Otín dresse la liste pour l'espace castillan (Lop 2003). Récemment, Vincent Tabbagh a proposé un bilan sur les évêques français (Tabbagh 2015) mais l'équivalent n'existe pas pour la péninsule Ibérique et les lignes de recherche de l'ouvrage ne s'orientent pas vers rapport avec le territoire. Voir, néanmoins, le mémoire d'Habilitation à Diriger les Recherches récemment soutenu par Anne Massoni, voir le compte-rendu dans Bouchaud 2016.

${ }^{22}$ La province ecclésiastique de Tarragone ne recoupe pas exactement les frontières du Principat de Catalogne. Elle inclut le diocèse de Valence -hors de l'espace catalan- et n'englobe pas celui d'Elne, Monjas 2008, note 10, p. 48.

${ }^{23}$ Ramon 1999-2000, pp. 2 et 99.

${ }^{24}$ Busqueta 2004, p. 211.

${ }^{25}$ Sureda 2007, p. 60.

${ }^{26}$ Sureda 2010.

${ }^{27}$ Fatjó 2001.
} 


\begin{tabular}{|l|c|c|}
\cline { 2 - 3 } \multicolumn{1}{c|}{} & $\begin{array}{c}\text { NOMBRE DE MEMBRES DU } \\
\text { CHAPITRE CATHÉDRAL }\end{array}$ & NOMBRE DE DIGNITÉs \\
\hline 1. Barcelone & 40 & 8 \\
\hline 2. Lérida & 25 & (non renseigné) \\
\hline 2. Gérone & 24 & 7 \\
\hline 3. Tarragone & 23 & 11 \\
\hline 4. Vic & 22 & 3 \\
\hline 5. Urgell & 20 ou 21 & (non renseigné) \\
\hline Tortose et Elne & (non renseigné) & (non renseigné) \\
\hline
\end{tabular}

Fig. 1. Effectifs des chapitres cathédraux catalans à la fin du Moyen Âge.

\begin{tabular}{|l|c|}
\hline \multicolumn{1}{|c|}{ VILLE } & $\begin{array}{c}\text { NOMBRE D’HABITANTS } \\
\text { (FIN DU XIV }^{\mathrm{E}} \text { SIÈCLE) }\end{array}$ \\
\hline 1. Barcelone & 35000 \\
\hline 2. Lérida & 11000 à 12000 \\
\hline 3. Tortose & 8000 à 10000 \\
\hline 4. Gérone & 8000 \\
\hline 5. Tarragone & 6000 à 7000 \\
\hline 6. Vic & 2500 à 4000 \\
\hline 7. Elne & 2000 \\
\hline Urgell & (non renseigné) \\
\hline
\end{tabular}

Fig. 2. Poids démographique des villes sièges d'évêchés en Catalogne à la fin du XIV e siècle.

Cette hiérarchie, appuyée sur les effectifs capitulaire, rejoint donc moins la hiérarchie religieuse que la hiérarchie urbaine catalane. D'un point de vue démographique et économique, Barcelone apparaît clairement comme la principale ville du Principat ${ }^{29}$. Au niveau politique, la cité est aussi le siège de la Diputació del General et joue un rôle majeur lorsque, au milieu du $\mathrm{XV}^{\mathrm{e}}$ siècle, elle accueille à la fois de la Diputació et le Conseil du Principat (deux institutions soulevées contre le roi) et se pose en meneuse du parti

${ }^{28}$ Selon les chiffres proposés par Reglà 1969, p. 276; Batlle 1988, p. 255.

${ }^{29}$ Bien que Barcelone soit en perte de vitesse par rapport à sa voisine Valence au XVe siècle, la ville demeure un port et un centre commercial important sur la côte méditerranéenne de la péninsule Ibérique et le principal centre économique du principat de Catalogne, voir l'étude classique de Carrère 1967, nuancée par Del Treppo 1972. 
anti-royaliste dans la guerre civile catalane de 1462-1472 ${ }^{30}$. L'importance du chapitre cathédral illustre alors, dans l'Église, cette place dominante de Barcelone.

En revanche, le chapitre cathédral de Barcelone jouit d'un pouvoir seigneurial bien plus faible que ses homologues. À Tarragone, les droits seigneuriaux sur la ville sont partagés entre l'archevêque et le roi, donnant lieu à de nombreux conflits entre les deux pouvoirs jusqu'en 1462, date à laquelle la ville s'émancipe de ces deux seigneurs et s'affirme comme une cité dotée de ses libertés politiques ${ }^{31}$. La situation est semblable pour Urgell qui, depuis 1278 est une co-seigneurie partagée entre l'évêque d'Urgell et les comtes de Foix (puis plus tard les rois de Navarre) ${ }^{32}$. À Vic, encore, l'évêque et le chapitre cathédral détiennent des droits seigneuriaux sur des châteaux et une portion du sol de la ville ${ }^{33}$. Barcelone, en revanche, au départ cité royale, obtient son autonomie en accumulant peu à peu un certain nombre de droits royaux (notamment dans le domaine fiscal), et n'est jamais cité ecclésiastique ${ }^{34}$. La cathédrale n'y est qu'une seigneurie foncière: les chanoines ne disposent d'aucun droit banal (sauf indirectement, via la Pia Almoina, dépendance de la cathédrale administrée par deux des chanoines du chapitre ${ }^{35}$ ). D'ailleurs, les ecclésiastiques ne siègent ni au Conseil des Cent ni au sein du collège des cinq conseillers qui disposent du pouvoir exécutif ${ }^{36}$.

$\mathrm{Au}$ vu de ces multiples critères de classement (effectifs, ampleur du pouvoir seigneurial de l'institution ${ }^{37}$ ), le siège épiscopal barcelonais se distin-

\footnotetext{
${ }^{30}$ Le Conseil du Principat et la Diputació del General, meneurs de l'opposition au roi Jean II, siègent à Barcelone et la cité déploie un jeu de négociation diplomatique pour se dégager du monarque dès les débuts de la guerre civile, Péquignot 2012a, pp. 163-165.

${ }^{31}$ Juncosa 2015, p. 21.

${ }^{32}$ Viader 2003.

${ }^{33}$ Le siège épiscopal de Vic possède notamment quatorze franqueses: des zones de la cité où les chanoines sont détenteurs de tous les droits seigneuriaux, Freedman 1983, pp. 78-80.

${ }^{34}$ Voir une réflexion sur la construction du pouvoir municipal à Barcelone dans: Orti 2000, pp. 24 et 26.

${ }^{35}$ Sur les domaines de la Pia Almoina barcelonaise au XIV ${ }^{\mathrm{e}}$ siècle, voir les conclusions de López 1998.

${ }^{36}$ Sur la structure du gouvernement municipal de Barcelone, voir Vicens 1936-1937, pp. 106-141.

${ }^{37}$ Faute d'étude sur la question, puisque les travaux sur l'Église de la Couronne d'Aragon et en particulier de la Catalogne se font rares, il n'est pas possible, à l'heure actuelle, de comparer la richesse du temporel des différentes cathédrales catalanes au Moyen Âge. Christian Hermann s'essaie à un classement des menses épiscopales ibériques en fonction de leur richesse en 1565 1575. La plus riche serait celle de Tarragone, suivie par celles de Tortose, Gérone puis Urgell, et enfin Vic et Barcelone, Hermann 1988, pp. 155-157. La mense épiscopale, néanmoins, renseigne sur la richesse des revenus de l'évêque mais pas sur l'ensemble des revenus de la cathédrale ni sur ceux des chanoines. Des études manquent encore pour élargir ces conclusions et les appliquer à l'ensemble des cathédrales catalanes médiévales.
} 
gue donc clairement de ses homologues. Il possède une claire prééminence numérique mais dispose d'un pouvoir moindre sur la ville et n'exerce aucune supériorité institutionnelle au sein de l’Église locale.

\subsection{Le poids des évêchés dans les "bras ecclésiastiques" des institutions politiques: une hiérarchie de l'influence?}

En Catalogne, la détention d'une prébende qualifie les chanoines cathédraux pour exercer, à titre personnel ou au nom de leur chapitre, une fonction politique aux assemblées catalanes des Corts et de la Diputació del General. Chacune est en effet constituée de représentants des trois états: le "bras militaire" (la noblesse), le "bras royal" (représentant les villes), mais aussi le clergé, regroupé dans le "bras ecclésiastique". Chaque évêché envoie ainsi des représentants aux Corts de Catalogne lorsqu'elles siègent. Pour la Diputació del General, les mandats, de trois ans pour le député et l'auditeur de comptes de chacun des "bras", sont personnels: l'ecclésiastique est nommé à titre individuel, non en représentation de son établissement. Jusqu'à la décennie 1450 , les députés et auditeurs de comptes sortants désignent leurs successeurs. À partir de 1458, et jusqu'à une réforme impulsée par le roi Ferdinand d'Aragon, les trois députés et les trois auditeurs désignent chacun un candidat pour l'une des six charges vacantes, secrètement et devant des témoins et le notaire de la Diputació. Ce dernier effectue un tirage au sort entre les candidats proposés. À partir de 1493, finalement, cette cooptation est encore rendue plus limitée: des commissions sont alors établies pour dresser une liste d'individus aptes à exercer des fonctions à la Diputació et un tirage au sort est effectué entre elles $^{38}$.

En définitive, avant les années 1490, la cooptation, totale ou limitée par un tirage au sort très réduit, reste donc la norme. La nomination d'un député ou d'un auditeur de compte ne doit par conséquent rien au hasard. Pour exercer des fonctions à la Diputació, il faut y avoir des contacts. Or, il n'y a pas de préséance entre les établissements religieux sélectionnés pour le "bras ecclésiastique". Barcelone et les autres évêchés, de même que les établissements religieux réguliers, devraient donc théoriquement avoir autant de chances les uns que les autres de compter l'un de leurs membres à la Diputació del General. Cependant, l'examen de la liste des députés et des auditeurs de comptes tout au long du XVe siècle (1413-1513) révèle une toute autre

${ }^{38}$ Pour l'évolution des modalités de nomination à la Diputació del General, voir Riera 2011, p. 67. 
réalité : bien plus de députés et d'auditeurs de comptes sont issus du chapitre de Barcelone que des autres sièges épiscopaux catalans. Sur les cinquante députés et auditeurs de comptes issus du clergé cathédral catalan, dix-huit sont évêques ou chanoines à Barcelone. Les autres évêchés sont moins représentés: Vic fournit huit membres à la Diputació, Tarragone cinq, Tortose, Gérone et Urgell y envoient chacun quatre religieux, Lérida trois et Elne deux ${ }^{39}$.

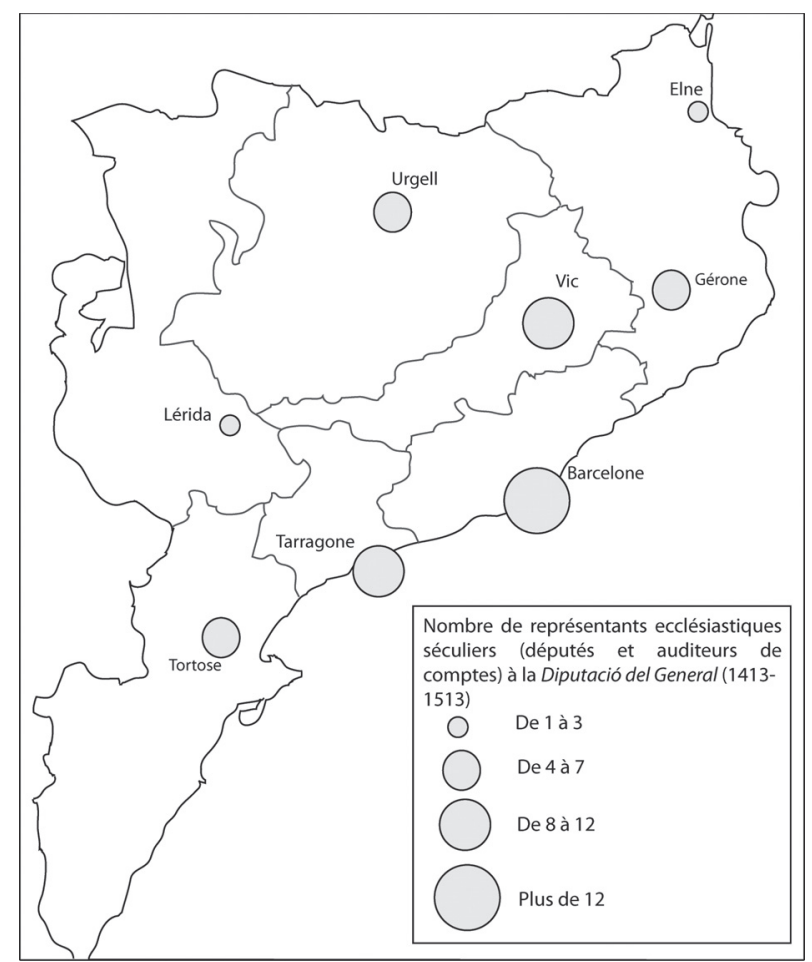

Fig. 3. Chapitres cathédraux d'origine des représentants ecclésiastiques séculiers à la Diputació del General de Catalogne (1413-1513).

La nette surreprésentation du haut clergé barcelonais transparaît clairement. Elle ne peut s'expliquer uniquement par l'importance numérique du clergé cathédral de la ville, puisque, comme on vient de le voir, avant 1493,

${ }^{39}$ Pour ces données, voir la liste des présidents et auditeurs de comptes de l'institution dans Solé 2003. S'y ajoutent les treize députés issus du clergé régulier (par exemple les abbés du monastère de Poblet ou de Sant Pere d'Àger), que nous ne retenons pas ici pour l'analyse. Le clergé régulier ne nourrit pas, en effet, le même lien définitoire avec une cité et fournit donc difficilement des informations sur la hiérarchisation des villes. 
les délégués n'étaient pas élus par tirage au sort mais cooptés. Il ne s'agit donc pas d'un simple effet statistique: les chanoines barcelonais sont davantage désignés par les députés sortants que leurs homologues. Cette surreprésentation barcelonaise n'est pas sans conséquence pour la ville elle-même: à travers ce haut clergé séculier, généralement uni par des liens familiaux voire de clientélisme aux élites urbaines ${ }^{40}$, la ville de Barcelone exerce un poids prégnant sur la Diputació del General.

Un réel classement des villes où siège un évêché en Catalogne se dessine. À une hiérarchie ecclésiastique théorique, qui place tous les évêchés dans une situation d'égalité sous la juridiction de l'archevêché de Tarragone, se superpose un autre classement, empirique, appuyé sur les caractéristiques des différentes cathédrales mais aussi sur le rayonnement politique des villes où elles sont implantées. Barcelone apparaît dans une situation dominante par rapport aux autres villes catalanes, que ce soit par son effectif ou par sa propension à envoyer des représentants ecclésiastiques aux assemblées politiques de la Diputació del General et des Corts de Catalogne. Les chanoines et évêques barcelonais, qui disposent, comme on l'a vu précédemment, d'un faible pouvoir seigneurial, mènent en revanche des carrières politiques locales, bien davantage que leurs homologues catalans.

Au sein de l'Église du Principat, l'institution capitulaire de Barcelone occupe donc une place à part. Elle compte des effectifs plus nombreux et entretient davantage de liens avec le pouvoir politique, à travers la carrière de ses membres. Peut-on pour autant parler de hiérarchie urbaine? Au-delà du simple classement, cette dernière notion implique en effet une situation d'interdépendance, des relations entre les villes observées, ainsi que l'existence de liens de rivalité ou de solidarité. Or, si l'on n'observe aucune relation directe entre les cathédrales catalanes, celles qui unissent leurs membres s'avèrent, en revanche, particulièrement significatives.

\section{SIĖGES ÉPISCOPAUX, RÉSEAUX D'HOMMES, RÉSEAUX DE VILLES}

\subsection{Les Corts, liens de solidarité et interdépendance des évêchés}

Le rayonnement du haut clergé d'une cité s'érige en reflet du poids politique de celle-ci. Le cas des Corts de Catalogne est révélateur: les sièges épiscopaux doivent y envoyer un représentant mais, en cas d'indis-

\footnotetext{
${ }^{40}$ Sur ces liens, voir l'analyse de Màrio Farelo sur Lisbonne, qui s'applique à la majorité des villes de l'Occident médiéval, Farelo 2012. Pour l'analyse du cas de Barcelone, voir Conesa 2017.
} 
ponibilité d'un évêque, celui-ci désigne un procurateur pour le représenter. La liste des procurateurs fait donc apparaître des liens privilégiés entre le prélat absent et son représentant ${ }^{41}$. Au long du $\mathrm{XV}^{\mathrm{e}}$ siècle, cinquante cas de procurations impliquant des évêques sont recensés. Dans quinze de ces cas, un évêque convoqué désigne pour représentant un chanoine membre d'un autre chapitre que le sien. En 1454, par exemple, Bartomeu Figueres, chanoine de Barcelone, est procurateur de l'évêque d'Urgell aux Corts de Barcelone. Pour la même assemblée, Joan Comes, chanoine de Vic, est procurateur de l'évêque d'Elne et, en 1460, l'est de celui de Gérone aux Corts de Lérida ${ }^{42}$.

Loin d'être anodines, ces procurations matérialisent une relation étroite entre les deux individus (l'évêque et son procurateur), mais égalemententre les différents chapitres cathédraux impliqués ${ }^{43}$. La procuration traduit en effet un lien privilégié entre le prélat et son délégué: probablement un lien de confiance, assurément un lien de connaissance. Or, cette connexion ne peut être pensée uniquement comme reliant deux individus à titre personnel. L'activité gestionnaire des chanoines au sein de leur cathédrale les oblige à côtoyer leurs confrères et à défendre des intérêts communs ${ }^{44}$. Ils sont eux aussi intrinsèquement connectés à leur chapitre cathédral: ils y nouent des contacts, en tirent des revenus ${ }^{45}$. C'est tout un réseau de connexions personnelles au sein

\footnotetext{
${ }^{41}$ Pour les données concernant les procurations pour siéger aux Corts, nous nous appuyons sur Morales 1999, qui synthétise les données de sources sur les Corts afin de présenter une brève notice de chaque représentant ecclésiastique.

${ }^{42}$ Morales 1999. Voir les registres biographiques par ordre alphabétique.

${ }^{43}$ Antonio Díaz montre le poids des réseaux personnels dans les modes de gouvernement des évêques cordouans du XVIe siècle. Pour instaurer sa politique épiscopale, le prélat s'appuie sur des chanoines fidèles, qu'il aide à obtenir des prébendes, voire l'épiscopat, dans d'autres diocèses, Díaz 2019, pp. 206-210. Les liens personnels, même quand il ne s'agit que de question d'administration (comme le fait de représenter un confrère à une assemblée) sont donc révélateurs d'un véritable réseau de connaissance et d'influence qui sous-tend les carrières et conditionne les modes de gouvernement des diocèses.

${ }^{44}$ En témoignent les nombreux conflits entre les chapitres cathédraux et les autorités municipales, qui traversent l'Occident médiéval. Les exemples pourraient se multiplier mais, pour nous limiter à la Couronne d'Aragon, nous citerons uniquement le cas de Majorque où, en 1478 , les chanoines et l'évêque font front commun contre des taxations imposées par le gouvernement municipal, Barceló 1999.

${ }^{45}$ Antonio Díaz a également montré, dans le cas de Cordoue au XVI ${ }^{\mathrm{e}}$ siècle, comment les revenus capitulaires servaient au haut clergé séculier à acquérir des terres et des biens fonciers en ville, voire à investir dans le crédit, Díaz 2009b. Ainsi à Majorque, dans la deuxième moitié du XVe siècle, le chanoine cathédral Gabriel Cerdà, élabore-t-il, grâce à ses revenus capitulaires, toute une stratégie d'acquisition de terres qu'il répartit ensuite dans sa famille à sa mort, Mai 2000. La situation se retrouve à Barcelone, comme le révèle le testament du chanoine Pere Ramon Loteres qui, grâce à sa prébende, parvient à acquérir sa maison, deux terrains, les droits seigneuriaux sur une terre et du mobilier, qu'il lègue à sa mort intégralement à sa famille (AHPNB, Joan Marc Miquel, 246/21, 4 février 1501, ff. 64r-66r).
} 
du haut clergé catalan qui apparaît. La procuration aux Corts matérialise bien un lien, au minimum indirect, entre l'évêque d'un siège épiscopal et le chapitre d'origine de son délégué.

Cette prégnance des connexions personnelles au sein du clergé s'observe tout particulièrement dans l'obtention des bénéfices ecclésiastiques ${ }^{46}$. Obtenir une charge implique d'être coopté par un chapitre, soutenu à Rome auprès du pape ${ }^{47}$, accepté par les pairs. Par conséquent, les grands ecclésiastiques s'insèrent, dès les débuts de leur carrière, dans un tissu dense de relations interpersonnelles. L'ampleur du népotisme au sein des hautes sphères de la hiérarchie suffit à démontrer l'importance des relations personnelles dans l'accession à une carrière ecclésiastique ${ }^{48}$. La désignation d'un confrère comme représentant à une assemblée des Corts ne peut donc être considérée comme anecdotique: elle s'insère pleinement dans cet ensemble de relations interpersonnelles qui tissent les carrières du haut clergé. Observer ces connexions met en lumière le réseau de liens qui unit les membres du haut clergé catalan d'un évêché à l'autre et, à travers eux, les chapitres euxmêmes ${ }^{49}$.

Une fois ces postulats établis, revenons à l'analyse des procurations pour les Corts. Le réseau qui apparaît est alors nettement centré sur Barcelone.

Pas moins d'onze procurations sont adressées à des chanoines du chapitre de Barcelone, quatre à des chanoines de Lérida (dont une qui concerne un chanoine détenant en même temps une prébende à Barcelone), trois à des chanoines de Vic, une seule à des chanoines de Tortose et aucune aux chanoines des autres chapitres ${ }^{50}$. Le retrait d'Elne peut s'expliquer par son appartenance à la province ecclésiastique de Narbonne et non de Tarra-

${ }^{46}$ L'importance des réseaux clientélaires dans l'attribution des bénéfices constitue le clergé en véritable réseau de connaissances et d'appui pour construire les carrières du haut clergé, Farelo 2005, p. 143; Guijarro 2008; Agúndez 2014.

${ }^{47}$ L'ampleur des démarches nécessaires auprès de Rome pour obtenir un canonicat a été mise en évidence par Díaz 2009a. Bien que ces observations se centrent sur l'époque moderne, post-tridentine, elles n'en éclairent pas moins les démarches personnelles, soutiens individuels et paiements, déjà existants à la fin du Moyen Âge, qui s'avèrent nécessaire pour une carrière dans le haut clergé séculier.

${ }^{48}$ Lind 1996, p. 170; Carocci 1999.

${ }^{49}$ Isabelle Rosé le démontrait pour le haut Moyen Âge, en analysant la trajectoire de l'abbé Odon de Cluny, qui construit son pouvoir abbatial en s'appuyant sur un ensemble de relations interpersonnelles. Ses déplacements et ses contacts personnels dessinent ainsi la géographie de son pouvoir, Rosé 2008.

${ }^{50}$ Nous tenons comptes ici des cumuls de prébendes: parfois, ce réseau relie plus de deux évêchés, puisque le chanoine cumule les prébendes. Ainsi en 1473-1479 et en 1493, le chanoine Martí Joan de Foixà représente-t-il l'évêque de Lérida, tout en étant lui-même chanoine à Barcelone et à Urgell. 
gone; celui de Gérone et Tarragone ne peut que refléter une moindre insertion personnelle de ses membres dans les réseaux de pouvoir ecclésiastique du Principat.

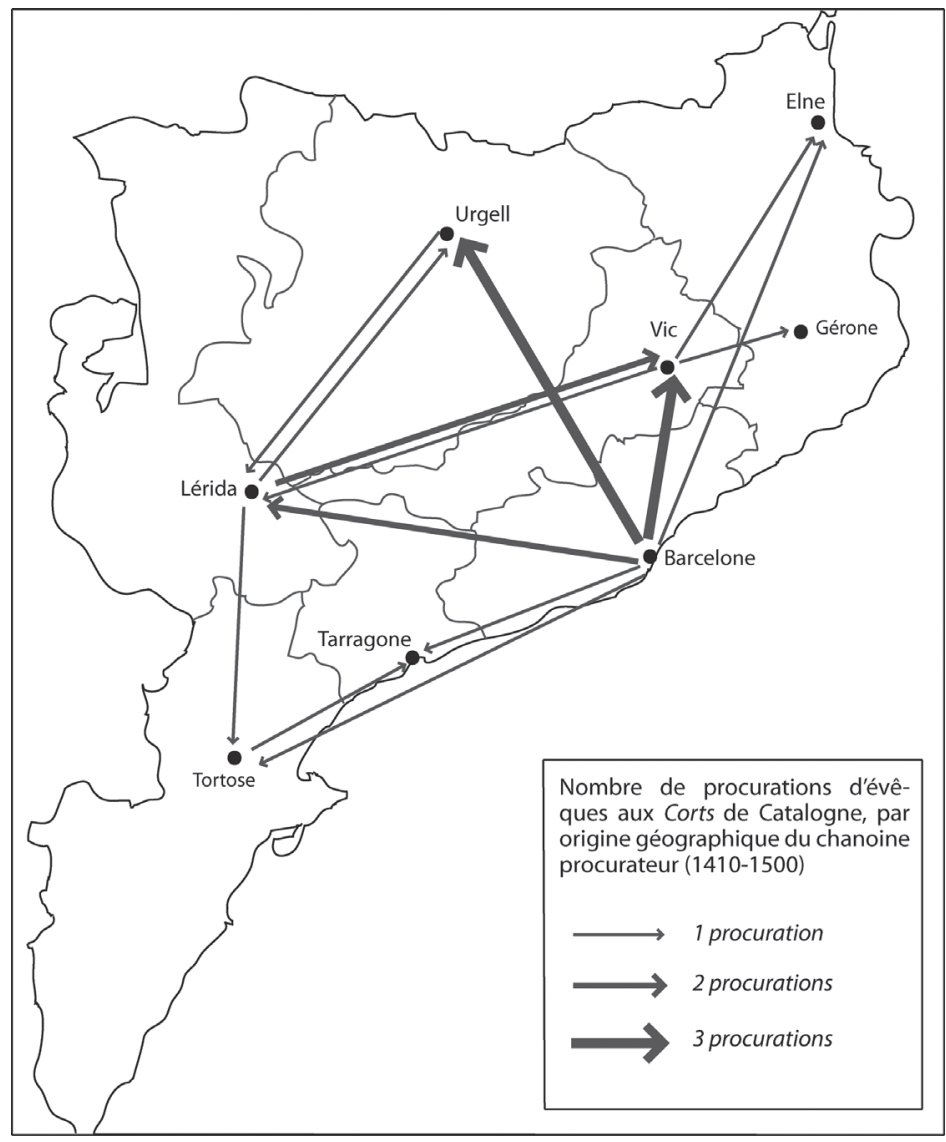

Fig. 4. Un réseau ecclésiastique catalan: les procurations des Corts $\left(\mathrm{XV}^{\mathrm{e}}\right.$ siècle).

En somme, une fois encore, Barcelone polarise l'ensemble du réseau d'évêchés catalans. Cette fois, ce réseau révèle une véritable hiérarchisation de l'influence des chapitres cathédraux en matière politique mais aussi en termes d'importance au sein du réseau de connexions interpersonnelles qui structure le haut clergé catalan. 


\subsection{Les carrières religieuses: entre réseaux personnels et réseau d'évêchés catalans}

Condamnés dès les conciles de Poitiers (1079), Clermont (1095), Latran III (1179) et Latran IV (1215), le cumul des bénéfices et son corollaire, la non-résidence des clercs, sont pourtant monnaie courante au bas Moyen Âge ${ }^{51}$. Les monographies se livrant à la prosopographie canoniale montrent que, généralement, au moins un quart des chanoines cumulent des prébendes dans d'autres diocèses, cette proportion variant d'un chapitre à l'autre ${ }^{52}$. Or, dans le cas catalan, il est frappant d'observer le caractère éminemment local de ces cumuls: à quelques rares exceptions près, les chanoines cumulent les prébendes exclusivement dans les limites de la Catalogne ${ }^{53}$. Ainsi, sur l'échantillon de 135 chanoines exerçant à Barcelone entre 1470 et 1500 dont on a pu retracer la carrière (à partir des sources de la cathédrale, de documentation diverse et de sondages au Vatican), deux seulement cumulent leur canonicat barcelonais avec une prébende hors de Catalogne: un à Majorque et un à Valence $^{54}$. Les autres, lorsqu'il y a cumul, restent rattachés à d'autres chapitres du Principat.

Parce qu'ils sont chanoines dans plusieurs chapitres catalans à la fois et parce qu'ils jouent un rôle dans la politique de chacune des villes où sont implantés leurs chapitres, les membres de ce haut clergé établissent bien, par leur carrière locale, des liens de complémentarité entre les villes. Bien que les cathédrales ne dialoguent pas du point de vue institutionnel, dans la pratique, il existe bien un réseau d'individus qui occupent le terrain des différentes charges ecclésiastiques d'importance, à l'échelle de la région. En outre, une nomination à une prébende n'est pas anodine, elle montre une intégration de l'individu à des réseaux d'influence. Toutes les prébendes catalanes n'ouvrent donc pas la voie à la même carrière.

${ }^{51}$ Wilkin 2005 , p. 41. Voir la synthèse bibliographique des travaux sur la question dans la note 1 , p. 41

${ }^{52}$ Cette situation concerne par exemple un quart des chanoines d'Angers mais $40 \%$ de ceux du Mans au Moyen Âge, Leloup 2013.

${ }^{53}$ Hors de Catalogne, au contraire, les bénéfices cumulés par les chanoines ont souvent tendance à être disséminés dans un espace bien plus vaste. Au Mans, par exemple, les chanoines détiennent fréquemment des prébendes dans l'ensemble du territoire du royaume de France, Leloup 2013. Ceux d'Amiens, de Reims et de Rouen cumulent davantage de bénéfices avec la cathédrale de Paris que dans leurs propres diocèses, Millet 2005.

${ }^{54}$ Voir, pour les détails de ces résultats, notre thèse de doctorat: Conesa 2017. 


\begin{tabular}{|c|c|}
\hline CHANOINE & CANONICATS CUMULÉS \\
\hline Antoni Agullana & Barcelone et Lérida ${ }^{55}$ \\
\hline Galceran Albanell & Barcelone et Tarragone ${ }^{56}$ \\
\hline Pere Boada & Barcelone et $\mathrm{Vic}^{57}$ \\
\hline Joan Cosidó & Barcelone et Tortose $^{58}$ \\
\hline Lluís Desplà & Barcelone, Elne ${ }^{59}$ \\
\hline Martí Joan de Foixà & Barcelone, Lérida et Urgel ${ }^{60}$ \\
\hline Pere Llopart & Barcelone, Urgel et Vic ${ }^{61}$ \\
\hline Joan Navarro & Barcelone, Urgel $^{62}$ \\
\hline Antoni Horts & Barcelone et Gérone $^{63}$ \\
\hline Gabriel Rovira & Barcelone, Gérone et Majorque ${ }^{64}$ \\
\hline Jordi Sanç & Barcelone, Vic et Valence $^{65}$ \\
\hline Joan Andreu Sorts & Barcelone, Tarragone, Urgell et Majorque ${ }^{66}$ \\
\hline Berenguer de Sos & Barcelone (et archevêque à Sassari) \\
\hline Bartomeu Travesset & Barcelone et Urgell $^{67}$ \\
\hline Bartomeu Vallescar & Barcelone et Gérone $^{68}$ \\
\hline
\end{tabular}

Fig. 5. Le cumul des prébendes en Catalogne: l'exemple de Barcelone entre 1472 et 1500 .

\section{3. Évêques et réseau d'évêchés catalans}

L’organisation du haut clergé séculier en réseau centré sur la Catalogne est particulièrement visible pour les évêques. Plusieurs mènent une carrière essentiellement catalane, en passant d'un évêché à l'autre. Ainsi par exemple, Jaume de

\footnotetext{
${ }^{55} \mathrm{ADB}$, sèrie testaments, Lib. definitio. testament. et piarum causarum, vol. 64, f. 150v.

${ }^{56}$ Ramon 1999-2000, p. 396.

${ }^{57}$ ASV, Reg. Vat. 528, f. 192v-194v et ADB, sèrie testaments, Lib. definitio. testament. et piarum causarum, vol. 70, f. 112r-113r.

${ }^{58}$ Rius 1927, p. 247.

${ }^{59}$ ASV, Reg. Lat. 665, f. 302r-303v et Salicrú 2003, pp. 264-266.

${ }^{60}$ AHPNB, Joan Vilana, Primus liber testamentorum (1480-1519) - 257.63, f. 102r pour la mention d'Urgell et, pour celle de Lérida, Aventín 2003, pp. 206-208.

${ }^{61}$ ASV, Reg. Vat. 528, f. 289v-290v.

${ }^{62}$ Sans 1994, p. 254.

${ }^{63}$ Rius 1927, p. 282.

${ }^{64}$ Ibidem, p. 292.

${ }^{65}$ Salicrú 2003, p. 271.

${ }^{66}$ Ramon 1999-2000, pp. 397 et 402 ; Rius 1927, p. 297; Cassanyes (à paraître).

${ }^{67}$ ASV, Reg. Suppl. 889, f. 292 v.- 293 r. et ADB, sèrie testaments, Lib. definitio. testament. et piarum causarum, vol. $67, \mathrm{f} .113 \mathrm{r}-114 \mathrm{r}$.

${ }^{68}$ ASV, Reg. Vat. 528, f. 289v-290v.
} 
Cardona i de Gandia est-il évêque de Vic (1445-1459), puis de Gérone (1459-1462) puis d'Urgell (1462-1466). Roderic de Borja (ou Borgia), pour sa part, est d'abord évêque d'Urgell (1467-1472) puis de Barcelone (1472-1478). Sur les douze évêques de Gérone qui se succèdent entre 1408 et 1506, sept occupent ensuite l'épiscopat dans un autre diocèse. Sur ces sept prélats, cinq le font en Catalogne ${ }^{69}$.

\begin{tabular}{|l|l|l|}
\hline \multicolumn{1}{|c|}{$\begin{array}{c}\text { DATE DE } \\
\text { L'ÉPISCOPAT }\end{array}$} & \multicolumn{1}{|c|}{ NOM DU PRÉLAT } & \multicolumn{1}{c|}{ SIÈGE ÉPISCOPAL SUIVANT } \\
\hline $1408-1409$ & Francesc de Blanes & Barcelone (Catalogne) \\
\hline $1409-1415$ & Ramon Descatllar & - \\
\hline $1415-1419$ & Dalmau de Mur & Tarragone (Catalogne) \\
\hline 1419 & Gonzalvo de Santamaría & Astorga (royaume de Castille) \\
\hline $1419-1429$ & Andreu Bertran & Barcelone (Catalogne) \\
\hline $1431-1436$ & Joan de Casanova & - \\
\hline $1436-1457$ & Bernat de Pau & - \\
\hline $1457-1458$ & Roderic de Borja & Valence (futur pape Alexandre VI) \\
\hline $1458-1459$ & Cosme de Montserrat & Vic (Catalogne) \\
\hline $1459-1462$ & Jaume de Cardona i de Gandia & Urgell (Catalogne) \\
\hline $1462-1484$ & Joan Margarit & - \\
\hline $1485-1506$ & $\begin{array}{l}\text { Berenguer de Pau i de } \\
\text { Perapertusa }\end{array}$ & \\
\hline
\end{tabular}

Fig. 6. La carrière des évêques de Gérone au XV siècle: des trajectoires surtout locales.

Le passage des évêques d'une cathédrale à l'autre au cours de leur carrière confirme donc ce que les carrières des chanoines catalans ébauchaient. D'une part, les carrières sont éminemment régionales. D'autre part, le recrutement est éloquent: il n'est pas rare qu'un évêque soit un ancien chanoine du chapitre. Joan Margarit, évêque de Gérone, en avait ainsi été chanoine. La carrière peut également se construire à l'échelle de plusieurs villes catalanes: le chanoine Dalmau de Mur détient ainsi une prébende à Gérone, avant d'accéder à l'épiscopat de cette ville, puis à celui de Tarragone, et enfin à celui de Saragosse (Aragon) $)^{70}$. Les chapitres catalans semblent bien constituer une manne de charges ecclésiastiques pour façonner une carrière, d'abord locale, qui dans certains cas prend une ampleur internationale (cardinalat, épiscopat). À Barcelone, en revanche, aucun chanoine n'accède à l'épiscopat dans la deuxième moitié du $X V^{\mathrm{e}}$ siècle. L'évêque est toujours non-résident, appelé à mener

\footnotetext{
${ }^{69}$ Pour reconstituer la liste des évêques, voir: Gams 1873; Eubel 1914.

${ }^{70}$ Morales 1999.
} 
sa carrière loin de Barcelone, notamment auprès du pape: Roderic de Borja (1472-1478) réside à la cour romaine, Gonzalo Fernández de Heredia (14781490) et Pere Garcia (1490-1505) sont non-résidents durant une grande part de leur épiscopat ${ }^{71}$. Les chanoines qui accèdent à l'épiscopat le font en dehors de leur diocèse; par exemple, Berenguer de Sos devient archevêque de Sassari (figure 5). L'évêché de Barcelone se distingue une fois de plus: il est tenu par des réseaux d'un autre niveau, non accessibles aux simples chanoines du diocèse ${ }^{72}$.

Le haut clergé séculier catalan n'en constitue pas moins un réseau d'hommes qui occupent les prébendes et dignités ecclésiastiques des sièges épiscopaux catalans, simultanément ou au long de leur carrière. Dans la pratique, ce sont ces individus qui administrent les différents établissements, qui portent leurs voix aux "bras ecclésiastique" des Corts et de la Diputació del General. Ces réseaux conditionnent, dans la pratique, l'accès aux postes et l'exercice des fonctions qui y sont rattachées. À ce titre, ils constituent alors un atout non négligeable pour la ville qui arriverait à en tirer parti.

\section{LE HAUT CLERGÉ SÉCULIER ET LE RAYONNEMENT POLITIQUE DES CENTRES URBAINS}

\subsection{Ville et haut clergé séculier: des échanges de bons procédés}

Le cas de Barcelone est particulièrement éclairant. Placés, comme on vient de le voir, au centre des relations interpersonnelles qui unissent les

\footnotetext{
${ }^{71}$ Sans 1994, p. 226; Aldea, Marín, Vives 1972,p. 192.

${ }^{72}$ La question se pose de savoir si cette spécificité barcelonaise et corrélée au mode de désignation des évêques. En l'état actuel des connaissances sur l'Église catalane médiévale, seules des hypothèses peuvent être formulées. On peut ainsi avancer que le pouvoir royal a davantage intérêt à intervenir et à garantir le siège épiscopal barcelonais à des individus de haut rang et fidèles à la monarchie, en raison de la puissance politique et économique de la ville. En effet, si la Catalogne a suscité peu d'études sur les nominations épiscopales, la péninsule Ibérique est héritière d'un long passé de contrôle des sièges épiscopaux par les souverains. Le pape entérine les désignations effectuées par les souverains, tout en tentant de placer ses propres candidats. En Castille par exemple, le recueil juridique des Siete Partidas établit certes la désignation épiscopale par les chapitres cathédraux mais, si les réserves pontificales se multiplient partir du XIV ${ }^{\mathrm{e}}$ siècle, les rois maintiennent en réalité un fort contrôle sur les nominations épiscopales, à travers l'exercice du "droit de supplication" entériné par la bulle Sedis apostolicae (1421). De la même façon, à la fin $\mathrm{du} \mathrm{XV}^{\mathrm{e}}$ siècle, les souverains Isabelle de Castille et Ferdinand d'Aragon accentuent leur contrôle sur les sièges épiscopaux en prenant soin de nommer des évêques fidèles à travers toute la péninsule, Hermann 1988; Arranz 2001; Fernández 2005; Rucquoi, 2009. Dans ce contexte, le contrôle du siège épiscopal barcelonais semble se poser comme un enjeu plus important pour les souverains que celui des évêchés voisins. On sait par exemple qu'en 1505, les chanoines de la cathédrale de Barcelone désignent l'un des leurs, Lluís Desplà, pour succéder à l'évêque Pere Garcia. Cette élection est néanmoins annulée et c'est Enric de Cardona, parent de plusieurs évêques catalans, qui est désigné à cette charge, sur présentation du roi Ferdinand (ACB, Perg., 3-4-87).
} 
membres du clergé des sièges épiscopaux catalans, les chanoines de la ville ne prennent, en revanche, aucune part officielle au gouvernement de la cité. Parce qu'ils relèvent du for ecclésiastique qui le leur interdit ${ }^{73}$, ils ne siègent ni au Conseil des Cent ni parmi les Conseillers et n'exercent aucun office royal ${ }^{74}$. Pourtant, dans la pratique, ils s'avèrent jouer un rôle privilégié d'intermédiaires pour certaines affaires de la politique municipale ${ }^{75}$. Les Correspondances des conseillers de Barcelone, conservées dans la série Lletres Closes des Archives Municipales de Barcelone et dépouillées pour cet article entre 1473 et 1493 , mettent ce rôle informel en évidence ${ }^{76}$. En de multiples occasions, la ville recourt à des chanoines cathédraux pour délivrer un message ou, le plus souvent, pour plaider la cause de Barcelone auprès d'une personnalité dont ils sont proches: le pape, le cardinal de Valence ou encore l'archevêque de Tarragone ${ }^{77}$. En 1474, par exemple, les Conseillers s'adressent au chanoine Ramon Dusai, pour lui demander d'intercéder auprès du roi en faveur du candidat qu'ils soutiennent dans une affaire d'attribution de prébende (un certain Pere Boscà $)^{78}$. Le clergé cathédral joue alors le rôle d'interface entre l'Église, d'une part, les élites politiques urbaines, de l'autre ${ }^{79}$. La capacité de ces dernières à mobiliser à leur avantage les réseaux personnels que les chanoines cathédraux de la ville possèdent dans l'Église catalane constitue un véritable mode de rayonnement de la cité barcelonaise.

${ }^{73}$ Ferro 1987, pp. 324-325.

${ }^{74}$ Dans la deuxième moitié du $\mathrm{XV}^{\mathrm{e}}$ siècle, le gouvernement municipal barcelonais relève du Conseil des Cents (lui-même doublé du conseil restreint dit el Trentenari): une assemblée de 128 représentants des différents estaments (états) de la population urbaine. Pour cette organisation institutionnelle, voir: Vicens 1936-1937, pp. 106-141.

${ }^{75}$ Voir l'analyse plus approfondie de cette intégration du haut clergé dans les réseaux politiques du gouvernement barcelonais dans Conesa 2016.

${ }^{76}$ La série AHCB, 1.B.VI-26 à 33 des archives municipales de Barcelone.

${ }^{77}$ Partant lui aussi du corpus des lettres expédiées par les cinq conseillers de Barcelone mais entre 1433 et 1550, Vicent Baydal Sala met en évidence l'existence d'un véritable réseau de pouvoir du gouvernement barcelonais, qui exerce ses fonctions en s'appuyant sur des destinataires stratégiques chargés de défendre les intérêts de la cité. La rhétorique employée dans ce cadre se caractérise par son efficacité et son adaptation rigoureuse au destinataire du courrier et à ses liens avec la cité, Baydal 2009.

${ }^{78}$ AHCB, 1.B.VI-26, f. 120r-121v. Voir les détails de l'affaire ainsi que d'autres exemples dans: Conesa 2017.

${ }^{79}$ Le rôle d'intermédiaires privilégiés qu'ont pu jouer les clercs pour établir des relations entre un pouvoir laïc et le haut clergé a été analysé par Jean-Louis Gazzaniga, mais dans le cas spécifique des relations nouées avec Rome. Dans le royaume de France, le roi n'hésite ainsi pas à envoyer des évêques fidèles en ambassade auprès du pape pour intervenir dans des questions de relations entre le Saint Siège et le royaume de France, telles que la Pragmatique sanction, la politique internationale ou encore les libertés de l'Église gallicane, Gazzaniga 1992, pp. 264266. On observe ici la même stratégie, déployée cette fois non par un monarque s'appuyant sur des évêques, mais par un gouvernement municipal s'appuyant sur des chanoines. 
Or, dans la rhétorique des lettres, le recours à ces ecclésiastiques est justifié par leur attachement personnel à la ville: c'est parce qu'ils appartiennent aux principaux lignages de la cité, ce qui implique qu'ils soient très préoccupés par son sort, que les conseillers recourent à eux. En 1475, le chanoine Dusai, que l'on vient de citer, est identifié dans les correspondances municipales comme un fils originaire de cette ville (Barcelone) ${ }^{80}$. C'est parce qu'il est une personne très méritante et liée par des liens familiaux dans cette ville que les conseillers, dit la lettre, ont confiance dans le fait qu'il leur concèdera son appui ${ }^{81}$. Dans une missive ultérieure, l'ensemble de la famille Dusai est mise à l'honneur en ce sens: votre famille montre que vous êtes bon citoyen et un fils de cette ville, prenant à cœur les intérêts de la ville ${ }^{82}$. Le lien de causalité entre l'origine barcelonaise du chanoine et les intérêts de la ville est clairement établi.

Les conseillers de Barcelone ne cachent pas non plus leur volonté d'interférer dans les désignations aux bénéfices ecclésiastiques locaux, au canonicat et à l'épiscopat. En 1473, ils plaident la cause de l'aspirant chanoine Boscà, fils d'une notable famille barcelonaise; en 1476-1477, ils soutiennent Gabriel Clapers à la succession du chanoine Feixes qui bénéficie des mêmes assises familiales, contre un aspirant chanoine étranger à la ville (Antoni Horts $^{83}$. En 1484, ils écrivent au roi pour soutenir la candidature du chanoine barcelonais Berenguer de Sos comme évêque ${ }^{84}$. Si la plupart de ces manœuvres échouent, l'on perçoit la volonté des échevins barcelonais de s'immiscer dans les nominations ecclésiastiques locales.

Les réseaux internes à l'Église catalane, que l'on a mis en évidence dans les pages précédentes, sont donc loin d'être déconnectés de la sphère du pouvoir politique municipal. Si les chanoines catalans constituent un réseau de connaissances et de coopération, ils entretiennent aussi des liens avec le gouvernement municipal barcelonais. Celui-ci tente d'avoir son mot à dire dans les nominations canoniales et, donc, de tisser des liens de solidarité avec les ecclésiastiques qui, ensuite, pourront en tisser avec leurs homologues des autres cités catalanes. La démarche des conseillers barcelonais assure alors le rayonnement de leur cité dans les réseaux de l'Église du Principat: les individus, désignés comme chanoines à Barcelone et qui détiennent, nous l'avons vu plus haut, une position dominante dans les réseaux du haut clergé régional, entretiennent des liens de coopération avec le gouvernement politique de la

\footnotetext{
${ }^{80}$ AHCB, 1.B.VI-27 f. 20r: "mossèn Ramon Dusay, fill originari d'aquesta ciutat".

${ }^{81}$ AHCB, A.B.VI-27 f. 20r: "persona meritant molt, aparentat en aquesta ciutat".

${ }^{82}$ AHCB, A.B.VI-27, f. 50v: "mostre la família vostra ésser bon ciutedà e fill de aquesta ciutat, reputant los interessos de la ciutat".

${ }^{83}$ AHCB, 1.B.VI-27, f. 149r-150r et AHCB, 1.B.VI-28, ff. 36r-37r.

${ }^{84}$ AHCB, 1.B-VI-31, f. 150r.
} 
cité. En d'autres termes, pour la ville de Barcelone, disposer d'un haut clergé séculier puissant et bien inséré dans les réseaux de pouvoir représente un véritable enjeu. Les liens tissés entre la cité et son haut clergé séculier permettent au gouvernement de la ville d'être en relation étroite avec des individus qui, via l'Église, sont eux-mêmes en contact avec les autres chapitres cathédraux catalans et qui, en outre, siègent aux assemblées politiques régionales que sont la Diputació del General et les Corts.

\subsection{Mobiliser les réseaux du haut clergé urbain: un moyen d'accéder à d'autres villes}

À plusieurs reprises, la ville de Barcelone mobilise donc les réseaux des chanoines de la ville pour obtenir gain de cause dans une affaire, en leur demandant de traiter pour elle auprès d'un individu puissant avec lequel son statut d'ecclésiastique le met en contact. Un exemple permet de l'observer de façon nette.

En 1478, un conflit oppose le gouvernement de Barcelone aux membres du clergé local à propos de leur participation à l'impôt indirect sur la viande ${ }^{85}$. L'affaire remonte jusqu'à l'archevêque de Tarragone, chargé de trancher la question. Pour faire valoir leur cause auprès du prélat et l'amener à considérer leurs doléances d'un œil favorable, les conseillers se tournent vers un certain Joan Miquel, chanoine tarragonais et familier du prélat, pour lui exposer l'affaire et lui demander d'intercéder pour eux auprès de l'archevêque. Les Conseillers néanmoins, s'adressent à lui parce qu'ils ont toute confiance dans le fait que, étant un enfant de cette ville autant que par préoccupation pour la justice dont [ils sont] certains que [sa] magnificence se préoccupe avec zèle, il saura prendre parti en faveur de Barcelone ${ }^{86}$. Pour emporter son adhésion, les conseillers n'hésitent pas à rappeler le devoir de leur destinataire, qui doit se comporter en bon fils et citoyen de cette ville ${ }^{87}$. C'est bien

${ }^{85}$ Pour les détails de l'affaire et son contexte précis, voir: Conesa 2017.

${ }^{86}$ AHCB, B.VI-28, f. 141v-142 r: 14 août 1478 "havents firmíssima confiança que axí per ésser vós fill de aquesta ciutat com per la justícia de la qual som certs vostra magnificència és molt zeladora".

87 "com a bon fill e ciutedà de aquesta ciutat". Cette rhétorique témoigne de l'habileté des conseillers barcelonais, qui adaptent leur argument à leur interlocuteur avec finesse. D'autres arguments sont ainsi mobilisés lorsque celui-ci vient d'un autre territoire de la Couronne d'Aragon, et les conseillers peuvent insister tour à tour sur l'amitié et la concorde pour amener leur contact à soutenir Barcelone, Baydal 2009, p. 10. Voir aussi la subtilité des stratégies de négociation et l'importance de la rhétorique déployée dans ce but dans: Péquignot 2012a. Le fait notable, ici, est précisément l'emploi d'une ligne argumentative associant le chanoine à sa ville natale afin qu'il intervienne en faveur de celle-ci auprès d'un confrère d'une autre cité. 
l'origine barcelonaise de Joan Miquel qui est avancée, non ses liens personnels avec les élites de la ville ou avec les conseillers eux-mêmes. La famille Miquel ne figure d'ailleurs pas dans les rangs de l'oligarchie barcelonaise et la lettre, de toute façon, ne fait aucune référence à l'existence d'un lien de parenté du chanoine avec les membres de l'élite sociale barcelonaise. C'est l'attachement à la cité elle-même qui est ici invoqué. Le chanoine, originaire de Barcelone, qui a mené sa carrière dans un évêché voisin, continue d'être mobilisé par les instances politiques barcelonaises, comme une plateforme de contact entre eux et l'institution ecclésiastique où il exerce, à Tarragone.

Voici bien la marque d'un réseau d'intérêt reliant les villes catalanes à travers leurs chapitres cathédraux. Les instances politiques municipales en ont pleinement conscience et n'hésitent pas à le mobiliser lorsqu'il leur est utile. Disposer d'un haut clergé séculier bien inséré dans les réseaux de l'Église catalane devient un enjeu pour une cité: ces individus apportent potentiellement à la ville l'accès à ce réseau interurbain de contacts internes à l’Église.

\section{CONCLUSION}

L'exemple de la Catalogne à la fin du Moyen Âge met en évidence la façon dont le poids du clergé cathédral d'une cité médiévale constitue un véritable critère pour mesurer l'importance relative d'une ville au sein d'un ensemble urbain. Moins qu'une relation de rivalité ou de concurrence entre les sièges épiscopaux, l'observation du réseau d'évêchés catalans révèle des liens de coopération au sein d'un réseau hiérarchisé, dont Barcelone constitue le centre névralgique. Les sièges d'évêchés, s'ils n'entretiennent aucun contact sur le plan institutionnel, ne pèsent pas tous du même poids dans la société catalane ni dans l'ensemble de relations interpersonnelles qui sous-tend le haut clergé régional. La position des cathédrales dans le classement urbain se mesure alors par l'intensité des connexions personnelles entretenues avec les autres évêchés et par le taux de présence des membres du chapitre dans le "bras ecclésiastique" des assemblées politiques catalanes: les Corts et la Diputació del General.

Ces critères d'analyse dessinent l'image d'une Catalogne très centrée sur elle-même: la plupart des carrières et des cumuls de prébendes se font à l'échelle des villes catalanes uniquement. Les chapitres ne jouissent pas tous du même poids démographique et n'offrent pas les mêmes opportunités de carrière à leurs membres. Ces différences sont significatives pour apprécier la hiérarchie urbaine de la région. Si ce réseau d'évêchés se limite largement à la Catalogne, sous l'autorité du siège métropolitain de Tarragone, il s'avère en réalité dominé par le chapitre de Barcelone. Les membres de la 
cathédrale barcelonaise, plus nombreux que leurs homologues des autres chapitres catalans, sont aussi plus volontiers choisis par leurs confrères de toute la Catalogne pour les représenter aux Corts. Leur capacité à nouer davantage de liens au sein du haut clergé catalan fournit au haut clergé barcelonais une plus grande représentation dans les assemblées politiques. Ses membres sont ainsi davantage présents à la Diputació del General que les chanoines des autres villes. Les conséquences de cet état de fait ne se limitent pas à la seule organisation interne de l'Église locale. Les instances politiques barcelonaises en tirent parti: le clergé cathédral barcelonais entretient des liens de solidarité avec le gouvernement de la ville, qui n'hésite pas à le mobiliser pour tenter de faire obtenir des faveurs à la cité.

La place de Barcelone dans la hiérarchisation des cités catalanes s'avère donc également un critère de hiérarchisation des villes sur le plan politique. Surreprésentée aux "bras ecclésiastiques" des institutions catalanes grâce à des députés ecclésiastiques, la cité de Barcelone essaie -avec un succès certes mitigé- de se réapproprier ce réseau ecclésiastique apporté par les chanoines originaires de la ville. Ce recours aux ecclésiastiques permet alors à la ville -définie en tant qu'entité politique et non plus comme simple lieu d'installation du chapitre cathédral- de rayonner sur l'espace catalan.

\section{BIBLIOGRAPHIE CITÉE}

Agúndez San Miguel, Leticia (2014), Carreras eclesiásticas y redes clientelares en la Castilla bajomedieval: la provisión de beneficios menores en el cabildo de la catedral de Burgos (1456-1470), "Anuario de Estudios Medievales" 44/2, pp. 665-687.

Aldea Vaquero, Quintin ; Marín Martínez, Tomás ; Vives Gatell, José (dir.) (1972), Diccionario de historia eclesiástica de España, t. 1, Madrid, Instituto Enrique Flórez.

Arranz Guzmán, Ana (2001), Las elecciones episcopales durante el reinado de Pedro I de Castilla, "En la España medieval" 24, pp. 421-461.

Aventín, Mercè (2003), Miquel Samsó, dans Solé i Sabaté, Josep Maria (dir.), Història de la Generalitat de Catalunya i dels seus presidents (13591518), Barcelone, Generalitat de Catalunya, vol. 1, pp. 206-208.

Balossino, Simone (2014), Évêques, communes, identité urbaine: quelques questions, dans Gilli, Patrick ; Salvatori, Enrica (dir.), Les identités urbaines au Moyen Âge. Regards sur les villes du Midi français, Turnhout, Brepols, pp. 123-129.

Barceló Crespí, Maria (1999), Conflicto entre los jurados y el obispo y cabildo de Mallorca (1478), "Anuario de Estudios Medievales” 29, p. 21-33. 
Batlle Gallart, Carme (1988), L'expansió baixmedieval (segles XIII-XV), dans Vilar, Pierre (dir.), Història de Catalunya, vol. 3, Barcelone, Edicions 62.

Baucells i Reig, Josep (1998-2001), Pia Almoina, dans Corts i Blay, Ramon; Galtès i Pujol, Joan; Manent i Segimon, Albert (dir.), Diccionari d'història eclesiàstica de Catalunya, Barcelone, Barcelone, Generalitat de Catalunya - Editorial Claret, vol. III, p. 85.

Baydal Sala, Vicent (2009), La xarxa epistolar del Consell municipal de Barcelona, 1433-1550, dans XI Congrés d'Història de Barcelona. La ciutat en xarxa Arxiu Històric de la Ciutat de Barcelona, Institut de Cultura, Ajuntament de Barcelona 1-3 de desembre de 2009, Barcelone, Arxiu Històric de la Ciutat de Barcelona.

Bouchaud, Pauline (2016), Compte-rendu de la soutenance d'habilitation à diriger des recherches d'Anne Massoni: Chanoines et chapitres séculiers dans la France médiévale, "Revue d'Histoire de l'Église de France" 102/1, pp. 222-228.

Busqueta Riu, Joan (2004), Història de Lleida, vol III: Baixa Edat Mitjana, Lérida, Pagès.

Caby, Cécile (2008), Religion urbaine et religion civique en Italie au Moyen Âge. Lieux, acteurs, pratiques, dans Crouzet-Pavan, Élisabeth, LecuppreDesjardin, Élodie (dir.), Villes de Flandre et d'Italie (XIIIe-XVIe siècle). Les enseignements d'une comparaison, Turnhout, Brepols, pp. 105-120.

Carocci, Sandro (1999), Il nepotismo nel medioevo. Papi, cardinali e famiglie nobili, Rome, Viella.

Carrère, Claude (1967), Barcelone centre économique à l'époque des difficultés. 1380-1462, 2 vols., Paris-La Haye, Mouton \& Co,

Cassanyes Roig, Albert (à paraître), El Capitol catedralici de Mallorca a la segona meitat del segle XV (1450-1495), "Anuario de Estudios Medievales".

Conde y Delgado de Molina, Rafael (1995), Fondos monásticos dispersos del Archivo de la Corona de Aragón, dans Memoria ecclesiae VI. Órdenes monásticas y archivos de la Iglesia (I), Oviedo, Asociación de archiveros de la Iglesia en España, pp. 147-156.

Conesa Soriano, Julia (2016), Le haut clergé dans les réseaux de l'élite dirigeante urbaine $d u$ bas Moyen Âge: chanoines, liens familiaux et réseaux politiques à Barcelone à la fin du XV siècle, dans Lemaître, Nicole (dir.), Réseaux formels et informels: du Moyen Âge à nos jours, Paris, éditions du CTHS, p. 43-53.

Conesa Soriano, Julia (2017), Entre l'Église et la ville: le chapitre et les chanoines de Barcelone au sortir de la guerre civile catalane (14721500), Université Paris-Sorbonne (thèse de doctorat). 
Les Corts a Catalunya: Actes del Congrés d'Historia Institucional, 28, 29 i 30 d'abril de 1988, Barcelone, Generalitat de Catalunya, 1991.

Del Treppo, Mario (1972), I mercanti catalani e l'espansione della Corona d'Aragona nel secolo XV, Naples, L'Arte tipografica.

Díaz Rodríguez, Antonio J. (2009a), El precio del nepotismo. Coadjutoría $y$ resigna en las catedrales andaluzas (ss. XVI-XVIII), "Chronica Nova" 35, pp. 287-309.

Díaz Rodríguez, Antonio J. (2009b), Inversión económica y gestión patrimonial particular entre los prebendados de la España moderna: Córdoba (1500-1800), "Obradoiro de Historia Moderna" 21, pp. 157-189.

Díaz Rodríguez Antonio J. (2012), El clero catedralicio en la España moderna: los miembros del cabildo de la catedral de Córdoba (14751808), Murcie, Universidad de Murcia.

Dumolyn, Jan (2010), Une idéologie urbaine bricolée en Flandre médiévale: les sept portes de Bruges dans le manuscrit Gruuthuse (début du $X V^{e}$ siècle), "Revue Belge De Philologie et d'Histoire" 88/4, pp. 1039-1084.

Eubel, Conradus (1914), Hierarchia Catholica Medii Aevi sive Summorum Pontificum, S.R.E. Cardinalium, Ecclesiarum Antistitum Series: ab anno 1431 usque ad annum 1503 perducta: et documentis tabularii praesertim Vaticani collecta, digesta. Monasterii, Sumptibus et typis Librariae Regensbergianae.

Farelo, Mário (2005), A quem são teúdos o barões e sages cónegos? Perspectivas sobre as redes de solidariedade no cabildo da sé de Lisboa (1277-1377), "Lusitania Sacra" 2a série, 27, pp. 141-183.

Farelo, Mário (2012), Les pouvoirs du parvis: pour une comparaison des élites ecclésiastique et municipale à Lisbonne (1325-1377), dans Soares da Cunha, Mafalda; Farrica, Fátima; Vasconcelos Vilar, Hermínia (dir.), Centros Periféricos de Poder na Europa do Sul (séculos XII-XVIII), Lisbonne, Edições Colibri - CIDEHUS-UÉ, pp. 115-141.

Fatjó Gómez, Pedro (2001), La Catedral de Barcelona en el siglo XVII: las estructuras y los hombres, Universitat de Barcelona (thèse de doctorat).

Fernández de Córdova Miralles, Álvaro (2005), Alejandro VI y los Reyes Católicos. Relaciones político-eclesiásticas (1492-1503), Rome, Edizioni Università della Santa Croce.

Ferrer i Mallol, Maria Teresa (2011), Història de la Generalitat de Catalunya. Dels orígens medievals a l'actualitat, 650 anys, Barcelone, Generalitat de Catalunya.

Ferro, Víctor (1987), El dret públic català. Les institucions a Catalunya fins al Decret de Nova Planta, Vic, Eumo Editorial. 
Freedman, Paul H. (1983), The Diocese of Vic. Tradition and regeneration in Medieval Catalonia, New Brunswick, Rutgers University Press.

Gams, Pius Bonifacius (1873), Series Episcoporum ecclesiae catholicae quotquot innotuerunt a beato Petro Apostolo, Ratisbonne, Manz.

Gaudemet, Jean (1979), Le gouvernement de l'Église à l'époque classique, tome VIII-2, de Le Bras, Gabriel; Gaudemet, Jean (dir.), Histoire du droit et des institutions de l'Église en Occident, Paris, Cujas.

Gazzaniga, Jean-Louis (1992), Les clercs au service de l'État dans la France $d u X V^{e}$ siècle, dans Krynen, Jacques; Rigaudière, Albert (dir.), Droits savants et pratiques françaises du pouvoir $\left(X I^{e}-X V^{e}\right.$ siècle), Bordeaux, PUB, pp. 253-278.

Guijarro González, Susana (2008), Jerarquía y redes sociales en la Castilla medieval: la provisión de beneficios eclesiásticos en el cabildo de la catedral de Burgos (1390-1440), "Anuario de Estudios Medievales" 38/1, pp. 271-299.

Hermann, Christian (1988), L'Église d'Espagne sous le patronage royal (1476-1834), Madrid, Casa de Velázquez.

Hurtado, Victor; Mestre, Jesús; Miserachs, Toni (1995), Altes d'història de Catalunya, Barcelone, Edicions 62.

Jaspert, Nikolas (2001), El Consell de Cent i les institucions eclesiàstiques, "Barcelona Quaderns d'Història" 4, pp. 108-127.

Jorge, Ana Maria (2001-2002), Fasti Ecclesiae Portugaliae: prosopografia do clero catedralício português: 1071-1325, "Lusitania Sacra" 13-14, pp. 665-666.

Juncosa, Eduard (2015), Estructura y dinámicas de poder en el señorío de Tarragona: creación y evolución de un dominio compartido (ca. 1180-1462), Barcelone, CSIC.

Leloup, Julien (2013), Les chanoines de la cathédrale du Mans et le cumul des bénéfices au XIVE siècle (1294-1378), "Annales de Bretagne et des Pays de l'Ouest" 120/1, p. 33-58.

Lind, Gunner (1996), Grands et petits amis: clientélisme et élites du pouvoir, dans Reinhard, Wolfgang (dir.), Les élites du pouvoir et la construction de l'État en Europe, Paris, PUF, pp. 163-203.

Lop Otín, María José (2003), Las catedrales y los cabildos catedralicios de la Corona de Castilla durante la Edad Media. Un balance historiográfico, "En la España medieval" 26, pp. 371-404.

López Pizcueta, Tomàs (1998), La Pia Almoina de Barcelona (1161-1350). Estudi d'un patrimoni eclesiàstic català baixmedieval, Barcelone, Fundació Noguera.

Mai i Forners, Antoni (2000), De pagesos a cavallers: l'extracció social i el patrimoni del cardenal Antoni Cerdà i del canonge Gabriel Cer- 
dà (segles XV-XVI), dans Barceló Crespí, Maria (dir.), Al tombant de l'edat mitjana. Tradició medieval i cultura humanista. Palma, del 15 al 17 de desembre de 1999, Palma, Institut d'Estudis Baleàrics, pp. 437-450.

Mazel, Florian (2008), Cujus dominus eius episcopatus? Pouvoir seigneurial et territoire diocésain (Xe-XIIIe siècle), dans Mazel, Florian (dir.), L'espace du diocèse. Genèse d'un territoire dans l'Occident médiéval (Ve-XIIIe siècle), Rennes, Presses Universitaires de Rennes, pp. 213-252.

Millet, Hélène (1982), Les chanoines du chapitre cathédral de Laon, 1272 1412, Rome, École Française de Rome.

Millet, Hélène (1996), Les Fasti Ecclesiae Gallicanae: des clés pour l'histoire des élites urbaines, dans Actes des congrès de la Société des historiens médiévistes de l'enseignement supérieur public, $27^{e}$ congrès, Rome, [s.n.], pp. 319-333.

Millet, Hélène (2005), Les Fasti Ecclesiae Gallicanae, dans Vaccaro, Luciano (dir.), Storia della Chiesa in Europa tra ordinamento politico-amministrativo e strutture ecclesiastiche, Brescia, École française de Rome et Fondazione Ambrosiana Paolo VI, p. 73-86.

Monjas Manso, Lluís (2008), La reforma eclesiàstica i religiosa de la província eclesiàstica tarraconense al llarg de la baixa edat mitjana. A través dels qüestionaris de visita pastoral, Barcelone, Fundació Noguera.

Monnet, Pierre (2010), Pour en finir avec la religion civique?, "Histoire urbaine" 27, pp. 107-120.

Morales Roca, Francisco José (1999), Prelados, abades mitrados, dignidades capitulares y caballeros de las Ordenes militares habilitados por el brazo eclesiástico en las Corts del Principado de Cataluña: dinastía Trastámara y de Austria: siglos XV y XVI, 2 vols., Madrid, Hidalguía.

Orti Gost, Pere (2000), El consell de Cent durant l'Edat Mitjana, "Barcelona Quaderns d'Història" 4, pp. 21-48.

Pellegrini, Michele (2004), Chiesa e città . Uomini, comunità e istituzioni nella società senese del XII e XIII secolo, Rome, Herder.

Péquignot, Stéphane (2012a), La pràticha de aquesta ciutat e principat. Réflexions sur l'action diplomatique des autorités catalanes à la veille et au début de la guerre civile (1461-1464), dans Naegle, Gisela (dir.), Frieden schaffen und sich verteidigen im Spätmittelalter/Faire la paix et se défendre à la fin du Moyen Âge, Munich, Oldenbourg, pp. 163-188 (Pariser Historische Studien; 98).

Péquignot, Stéphane (2012b), Le travail de négociation à Barcelone au XVe siècle, "Revue de synthèse" 133/6-2, pp. 215-233. 
Péquignot, Stéphane (2016), "No hay nada" ou "la Catalogne, source intarissable"? Réflexions sur une expérience de recherche entre abondance et absence d'archives, dans Grévin, Benoît; Mairey, Aude (éd.), Le Moyen Âge dans le texte. Cinq ans d'histoire textuelle au Laboratoire de médiévistique occidentale, Paris, Publications de la Sorbonne, pp. 193-212.

Ramon i Viñes, Salvador (1999-2000), Canonges, comensals $i$ beneficiats de la Seu de Tarragona, "Butlletí Arqueològic de la Reial Societat Arqueològica Tarraconense" 21-22, pp.241-338.

Reglà Joan (dir.) (1969), Història de Catalunya, t. I, Barcelone, Editorial Aedos.

Riera i Melis Antoni (2011), La Diputació del General de Catalunya, 1412 1458. Desenvolupament de les estructures i ampliació de les competències, dans Ferrer i Mallol, Maria Teresa (dir.), Història de la Generalitat de Catalunya. Dels orígens medievals a l'actualitat, 650 anys, Barcelone, Generalitat de Catalunya, pp. 43-73.

Rius i Serra, Josep (1927), Catalanes y aragoneses en la corte de Calixto III, "Analecta Sacra Tarraconensia" 3 pp. 193-330.

Rosé, Isabelle (2008), Construire une société seigneuriale. Itinéraire et ecclésiologie de l'abbé Odon de Cluny (fin du IXe-milieu du Xe siècle), Turnhout, Brepols.

Sabanés i Fernàndez, Roser (2009), Els concilis ilerdenses de la província eclesiàstica tarraconense a l'edat mitjana (546-1460), Barcelone, Fundació, Noguera.

Salicrú i Lluch, Roser (2003), Anys de transició, dans Solé i Sabaté, Josep Maria (dir.), Història de la Generalitat de Catalunya i dels seus presidents, Barcelone, Enciclopèdia Catalana, vol.1, pp. 233-287.

Sánchez de Movellán Torent, Isabel (2004), La Diputació del General de Catalunya, 1413-1479, Barcelone, Institut d'Estudis Catalans.

Sans Travé, Josep María (éd.) (1994), Dietaris de la Generalitat de Catalunya (1411-1714), vol. I (1411-1539), Barcelone, Generalitat de Catalunya.

Solé i Sabaté, Josep Maria (dir.) (2003), Història de la Generalitat de Catalunya $i$ dels seus presidents, vol.1, Barcelone, Enciclopèdia Catalana.

Stabel, Peter (2000), Urbanization and its Consequences: the Urban Region in Late Medieval Flanders, dans Ainsworth, Peter; Scott, Tom (dir.), Regions and Landscapes: Reality and Imagination in Late Medieval and Early Modern Europe, Bern, Peter Lang, pp. 177-203.

Sureda Jubany, Marc (2007), La Catedral i la Ciutat, dels orígens medievals al segle XVIII, dans Església, societat i poder a Girona. Segles XVIXX, Gérone, Ajuntament de Girona, pp. 37-92. 
Sureda i Jubany, Marc (2010), La catedral de Vic a les darreries del segle XIV. Edició i comentari de la visita pastoral de 1388, "Miscel-lània litúrgica catalana" 18, pp. 323-361.

Tabbagh, Vincent (2015), Les évêques dans le royaume de France au $X I V^{e}$ siècle, Dijon, Éditions Universitaires de Dijon.

Torra Pérez, Alberto (1995), Fondos documentales monásticos en el Archivo de la Corona de Aragón, dans Memoria ecclesiae VI. Órdenes monásticas y archivos de la Iglesia (I), Oviedo, Asociación de archiveros de la Iglesia en España, pp. 121-146.

Vauchez, André (1995), Introduction, dans Vauchez, André (dir.), La religion civique à l'époque médiévale et moderne (chrétienté et islam): actes du colloque, Nanterre, 21-23 juin 1993, Rome, École française de Rome.

Verger Jacques, Le transfert de modèles d'organisation de l'Église à l'État à la fin du Moyen Âge, dans Genet, Jean-Philippe; Vincent, Bernard (dir.), État et Église dans la genèse de l'État moderne, Madrid, Casa de Velázquez, 1986, pp. 31-41.

Viader, Roland (2003), L'Andorre du IXe au XIV siècle: montagne, féodalité et communautés, Toulouse, Presses universitaires du Mirail.

Vicens Vives, Jaume (1936-1937), Ferran II i la ciutat de Barcelona, 14791516, 3 vols., Barcelone, Tipografia Emporium.

Wilkin, Alexis (2005), Fratres et canonici. Le problème de la dissolution de la vie commune des chanoines, "Le Moyen Âge" 111, pp. 41-58.

Fecha de recepción del artículo: octubre 2017

Fecha de aceptación y versión final: marzo 2018 